\title{
Funbosque: remuneração dos professores de uma fundação pública para oferta de educação ambiental nas ilhas de Belém/PA ${ }^{1}$
}

\section{Resumo}

O artigo analisa a composição e evolução da remuneração dos professores da Fundação Centro de Referência em Educação Ambiental Escola Bosque Professor Eidorfe Moreira de Belém/PA, compreendida como condição objetiva de realização e valorização do trabalho docente. O período analisado foi de 2009 a 2019, a metodologia utilizada foi o materialismo histórico dialético. Concluise que a remuneração inicial dos professores da Funbosque ainda garante atratividade na carreira, visto que apresenta valores superiores àqueles pagos a professores da mesma rede de ensino, que possuem vínculo com outras escolas da rede, bem como às médias recebidas por professores de redes estaduais, municipais e federal da região Norte e Brasil. Contudo, é importante destacar que a remuneração dos professores da Funbosque é composta em sua maior parte $(67,2 \%$ em média) por gratificações, o que pode gerar impactos imediatos e futuros na remuneração destes profissionais, haja vista se tratar de elemento transitório, que pode ser retirado a qualquer tempo, como no momento da aposentadoria.

Palavras-chave: Financiamento da Educação. Remuneração de Professores. Valorização Docente.

\section{Funbosque: remuneration of teachers from a public foundation for providing environmental education in the islands of Belém/PA}

\begin{abstract}
This paper article the composition and evolution of the remuneration of teachers at the Reference Center for Environmental Education at Escola Bosque Professor Eidorfe Moreira de Belém/PA, understood as an objective condition for carrying out and valuing the teaching work. The period analyzed was from 2009 to 2019; the methodology used was the dialectical-historical materialism. It is concluded that the initial remuneration of Funbosque teachers still guarantees attractiveness in the career, as it presents values higher than those paid to teachers from the same educational network, who have links with other schools in the network, as well as the averages received by teachers from networks state, municipal and federal of the North region and Brazil. However, it is important to highlight that the remuneration of Funbosque teachers is composed mostly ( $67.2 \%$ on average) by bonuses, which can generate immediate and future impacts on the remuneration of these professionals, given that it is a transitory element, which can be withdrawn at any time, such as upon retirement.
\end{abstract}

Keywords: Education Financing. Teachers' Remuneration. Teacher Appreciation.

\footnotetext{
Esta discussão é parte integrante da discussão feita na tese de doutorado intitulada Carreira, Remuneração e Condições de Trabalho dos Professores da Fundação Centro de Referência em Educação Ambiental Escola Bosque Professor Eidorfe Moreira de Belém-PA, desenvolvida junto ao Programa de Pós-Graduação em Educação da Universidade Federal do Pará.
} 


\section{Introdução}

O presente artigo tem como objetivo analisar a composição e evolução da remuneração dos professores da Fundação Centro de Referência em Educação Ambiental Escola Bosque Professor Eidorfe Moreira de Belém/PA (Funbosque). Esses dois elementos são compreendidos por nós como condições objetivas de realização e valorização do trabalho docente, uma vez que demarcam condições materiais de sobrevivência e a situação em que se encontra a profissão docente atualmente no Brasil no que se refere à atratividade da carreira.

O período analisado foi de 2009 a 2019, sendo o ano inicial da série histórica (2009) escolhido por se tratar de marco referencial para a remuneração de professores brasileiros, ano de implementação da Lei $n^{\circ} 11.738 / 2008$, que instituiu o Piso Salarial Profissional Nacional (PSPN) para os profissionais do magistério público da educação básica e regulamentou disposição constitucional que há anos aguardava por detalhamento em lei, bem como coincidir também com o ano seguinte ao primeiro concurso realizado para professores dessa Fundação.

A metodologia utilizada na análise foi qualitativa, com análise de dados salariais e de remuneração retirados diretamente dos contracheques dos professores da Funbosque. Para melhor compreensão e contextualização do tema em análise, optamos por dividir a discussão em três partes, a saber: i) Breve apresentação do lócus da pesquisa, a Funbosque; ii) Caracterização do perfil de professor que a Funbosque almejava ter em seu quadro quando de sua proposta de criação e projeto pedagógico; iii) Análise da composição e evolução da remuneração docente da Funbosque.

\section{O Lócus da Pesquisa}

A Funbosque foi concebida e inaugurada em 1995, na gestão do prefeito Hélio da Mota Gueiros (Partido da Frente Liberal - PFL), e foi pensada alinhada aos pressupostos de meio ambiente contemplados na Eco-92, a saber, ser referência, na América Latina, de instituição promotora de educação ambiental, capaz de mudar as concepções de meio ambiente e educação no município de Belém (BELÉM, 1995).

Localizada na ilha de Caratateua, pertencente ao Distrito Administrativo do Outeiro (DAOUT), a Funbosque tem sua origem histórica ligada diretamente aos movimentos sociais insulares, com o desejo da população local de efetivação de uma proposta de escola que pudesse ajudar os seus residentes a nela permanecer, em condições dignas de existência (SILVA, 2007).

Silva (2007, p. 05) chama-nos atenção para o fato de que, à época de apresentação da proposta da Escola Bosque:

[...] vivia-se sob o espírito das preocupações com os problemas ambientais globais discutidos e divulgados amplamente a partir da realização da Conferência sobre Meio Ambiente e Desenvolvimento Humano - a ECO 92 realizado no Brasil, no Rio de Janeiro. A cidade de Belém assumiu um compromisso com a minimização dos problemas sócioambientais e com a construção de políticas de sustentabilidade para as populações insulares, e assim, entrou para a história da Educação Ambiental através da criação da Escola Bosque. 
A Lei Orgânica do Município de Belém, de 1990, em seu Capítulo VI, trata exclusivamente de meio ambiente e, no seu artigo 160 , inciso $\mathrm{V}$, estabelece como uma de suas prioridades "estimular a Educação Ambiental nos níveis de ensino mantidos pelo município e a conscientização pública para a preservação do meio ambiente". Com base nesses preceitos, na década de 1990, a prefeitura municipal criou secretarias e fundações com atribuições relacionadas ao meio ambiente; dentre elas a Funbosque, localizada na ilha de Caratateua, distrito de Outeiro.

A partir desses marcos legais, a educação ambiental no município de Belém passou a ser vista como estratégica para o desenvolvimento local da região das ilhas, sendo um importante instrumento de promoção da consciência ambiental, assim como estratégia fundamental para criar e aplicar de forma mais eficaz e sustentável o processo de integração homem-natureza (BELÉM, 1995).

A Funbosque atendeu inicialmente 700 alunos, visto que sua proposta inicial era de educação em tempo integral, e funcionou em acordo à proposta original de sua criação pelo período de apenas um ano (1996), pois no ano seguinte a sua fundação, em 1997, a gestão do município de Belém mudou. Assim, saiu o "pai" do projeto Escola Bosque - Hélio Gueiros - e assumiu como prefeito Edmilson Rodrigues (Partido dos Trabalhadores - PT). Assim, a Funbosque passou por um processo de mudanças, instituído pelo novo prefeito, que via na Fundação um projeto de Educação Ambiental elitista, visto que atendia poucos alunos em uma comunidade que necessitava de maior oferta de vagas.

Assim, iniciou a mudança na proposta da escola, que atenderia mais alunos e se organizaria nas mesmas bases das demais escolas do município de Belém, adotando a proposta de "Escola Cabana"2 do PT. Nesse processo, a sede da Fundação passou a atender o dobro de alunos que atendia até então (de apenas 700, passou a atender 1.400), e a agregar algumas escolas anexas, dentre elas cinco unidades pedagógicas, localizadas nas ilhas do arquipélago do Guajará (Jutuba, Paquetá e Cotijuba) e que eram escolas municipais. Estas permanecem até hoje sob sua responsabilidade e encontram-se distribuídas de acordo com o quadro abaixo:

Quadro 01 - Localização das unidades pedagógicas das ilhas da FUNBOSQUE

\begin{tabular}{|c|c|}
\hline Ilha & Unidade Pedagógica (UP) \\
\hline Jutuba & UP Jutuba II \\
\hline Paquetá & UP Jamaci \\
\hline Cotijuba & UP Faveira, UP Flexeira e UP Seringal \\
\hline
\end{tabular}

Fonte: PPP da Funbosque (2016).

A Fundação continuou expandindo suas atividades e atende atualmente, segundo dados fornecidos pela secretaria da instituição, o total de 2.100 alunos nos turnos da manhã, tarde e noite, ofertando da Educação Infantil ao Ensino Médio técnico, com 135 professores, entre efetivos e contratados em regime de trabalho temporário.

2 A 'Escola cabana' foi uma experiência na área de educação, iniciada em 1997, na primeira das duas gestões consecutivas do Partido dos Trabalhadores na Prefeitura de Belém, com a intenção de vivenciar um movimento de reorientação curricular de forma coletiva, com a partição de educadores da Rede Municipal de Educação de Belém e de outros segmentos da sociedade. Apoiava-se no ideário do histórico movimento da Cabanagem, ocorrido no Pará do século XVIII, inspirado nos princípios de justiça social e numa sociedade mais igualitária. 


\section{O Perfil de Professor Almejado}

Para a construção do projeto pedagógico da Funbosque, a Prefeitura de Belém, por meio de sua secretária de educação à época, Terezinha Gueiros, contratou o educador Pedro Demo e o incumbiu da tarefa de pensar não só a proposta pedagógica, bem como de nela delinear o perfil de professor almejado para trabalhar nesta Fundação (REIS, 2009).

Demo (1996) argumentava - em relação ao tipo de professor que a Funbosque almejava - que esse profissional deveria ter seu fazer pedagógico centrado na relação reconstrutiva do conhecimento, considerando uma cidadania que nutre e se potencializa na energia reconstrutiva do conhecimento, para possibilitar ao aluno a intervenção e mudança da realidade. Ainda, segundo o autor, para atingir tal objetivo, seria necessário mais que apenas envolvimento político, mais que palavras e conhecimento repassado mimeticamente, não seria mais possível tornar-se professor apenas com domínio repassado de conteúdo, o professor da Funbosque deveria dominar a competência substancial de renovar os conteúdos, de teor mais propedêutico, saber pensar, para melhor intervir e inovar (DEMO, 1996).

Com base nesse perfil de professor, foram estabelecidos alguns pré-requisitos necessários aos futuros docentes da Funbosque, instituídos como parâmetros da competência formal e política, em particular: i) domínio em pesquisa (capacidade de manejar conhecimento ativamente como sujeito, não o mero repasse de conteúdo; capacidade de estar dentro do contexto inovativo, acompanhando o ritmo da ciência; capacidade de conjugar conhecimento e educação em matriz única e global, sem separação entre teoria e prática ou cidadania e aprendizagem); ii) elaboração própria (construir a condição necessária da mudança didática concreta com superação da aula meramente expositiva; elaborar projeto pedagógico próprio; elaborar material didático próprio; teorização das práticas; atualização permanente; manejo da instrumentação eletrônica; avaliação permanente da aprendizagem do aluno; cultivo da interdisciplinaridade) (DEMO, 1996).

Outras propostas em torno da figura docente, que envolviam aspectos como jornada de trabalho, formação continuada, carreira e remuneração, e tidas como inovações na proposta de criação da Funbosque, foram: i) o professor deveria ser exclusivo da escola durante o dia, para evitar o "docente biscateiro", e acentuar a dedicação integral à tarefa de educar; ii) ganharia sensivelmente mais que a média municipal, para que se pudesse atrair os melhores docentes, privilegiando o mérito acadêmico; iii) a aula seria mais longa para possibilitar as inovações didáticas necessárias; iv) a cada semestre o professor teria o direito de estudar em curso de pelo menos 80 horas para manter seu processo próprio de aprendizagem; v) deveria reelaborar seu projeto pedagógico de maneira permanente; vi) seria avaliado considerando prioritariamente o mérito acadêmico (DEMO, 1996).

Em sua proposta de criação, os idealizadores da Funbosque reivindicavam que o reconhecimento da qualidade da escola dependia da qualidade dos docentes, o que justificaria o pagamento de uma remuneração diferenciada a estes profissionais, que deveriam ser poucos e bons, um corpo docente enxuto, pois "[...] um número desnecessário de docentes, além de sobrecarregar o orçamento e dar argumento ao rebaixamento salarial, obstaculiza o cuidado mais pessoal que se deve dar a cada um" (DEMO, 1996, p. 28).

A questão da remuneração diferenciada dos docentes justificava-se, ainda, pelo compromisso da Funbosque no "[...] cuidado zeloso em torno do professor, por ser ele a chave 
da qualidade da aprendizagem do aluno" (DEMO, 1996, p. 29), bem como para comprovar que a remuneração condigna dos docentes se constituiria em fator crucial de bom desempenho, pois seria parte de sua cidadania.

\title{
Composição da Remuneração dos Professores da Funbosque
}

A remuneração dos professores da Funbosque, assim como a carreira, é regulamentada por diferentes normatizações. A Lei $n^{\circ}$. 7.502, de 20 de dezembro de 1990, que dispõe sobre o Estatuto dos Funcionários Públicos do município de Belém, conceitua vencimento como "[...] a retribuição pecuniária pelo desempenho efetivo do trabalho no exercício de cargo público e corresponde ao valor fixado em lei" (Artigo 52 da Lei $n^{\circ}$. 7.502/1990). Remuneração é conceituada como "[...] o vencimento acrescido das gratificações e demais vantagens de caráter permanente atribuídas ao funcionário pelo exercício de cargo público" (Artigo 53 da Lei $n^{\circ}$. 7.502/1990). A compreensão sobre os termos vencimento-base e remuneração postos nessa legislação coincide com o entendimento de Sales e França (2018, p. 467), para quem:

\begin{abstract}
O vencimento representa a parte fixa do montante recebido pelo docente ao final do mês, sem qualquer tipo de acréscimo. Portanto, a política de reajuste salarial incide diretamente sobre esse elemento no contracheque. No caso da remuneração, ela representa o montante recebido, incluindo o vencimento e outros componentes recebidos pelo trabalhador, por exemplo, as gratificações, os abonos, entre outros.
\end{abstract}

No que se refere às vantagens de ordem pecuniária, o artigo 61 da Lei $n^{\circ}$. 7.502/1990 determina que "poderão ser atribuídas ao funcionário, na forma que dispuser o regulamento, as seguintes vantagens: I - gratificações; II - adicionais; e III - indenizações".

Aos funcionários públicos do município de Belém poderão ser concedidas as seguintes gratificações, segundo o artigo 62 da Lei $n^{\circ}$. 7.502/1990:

I - por regime especial de trabalho:

a) em tempo integral; e

b) em dedicação exclusiva;

II - por atividades especiais:

a) de função;

b) de localização especial de trabalho, na forma prevista em regulamento;

c) pelo exercício de atividades em condições insalubres ou perigosas;

d) de elaboração de trabalho técnico especializado, na forma prevista em regulamento;

e

e) de fiscalização ou coordenação de processos seletivos, na forma prevista em regulamento;

III - por produtividade;

IV - por serviço extraordinário;

$\checkmark$ - gratificação natalina; e

VI - gratificação de permanência.

Os funcionários públicos do município de Belém, segundo o que determina o artigo 79 da Lei $n^{\circ}$. 7.502/1990, farão jus aos seguintes adicionais:

I - adicional por tempo de serviço;

I - adicional de férias;

III - adicional de escolaridade; 
IV - adicional de turno; e

$\checkmark$ - adicional de cargo em comissão.

O adicional por tempo de serviço será devido ao funcionário público do município de Belém por triênio de efetivo exercício, até o máximo de doze. Esses adicionais serão calculados sobre a remuneração do cargo, nas seguintes proporções:

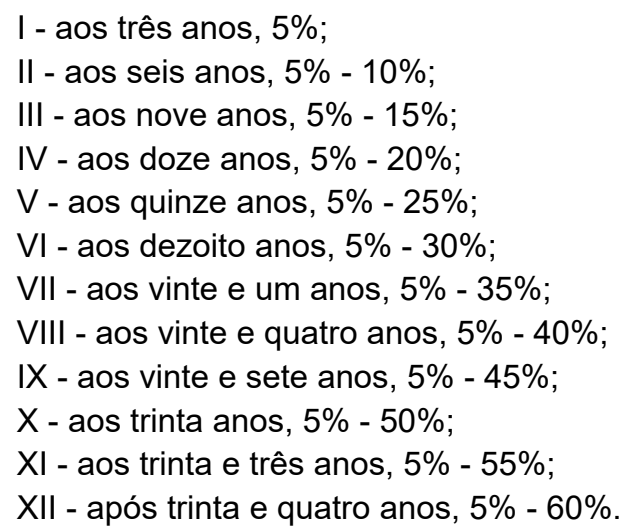

Contudo, o parágrafo único do artigo 53 da Lei $n^{\circ}$. 7.502/1990 ressalta que "as indenizações, auxílios e demais vantagens ou gratificações de caráter eventual não integram a remuneração". Trata-se de ganhos eventuais como, por exemplo, gratificações decorrentes de cargo, auxílio natalidade, entre outros.

Nenhum desconto pode incidir sobre a remuneração ou provento do servidor municipal, salvo por imposição legal ou mandato judicial (Artigo 57 da Lei $n^{\circ}$. 7.502/1990). Se houver autorização do funcionário, há a possibilidade de haver consignação em folha de pagamento a favor de terceiros, cabendo autorização a critério da administração, na forma estabelecida em regulamento (Parágrafo único do artigo 57 da Lei $n^{\circ}$. 7.502/1990).

Segundo a Lei Ordinária n. ${ }^{\circ} 7.528$, de 05 de agosto de 1991, que dispõe sobre o Estatuto do Magistério do município de Belém, aos funcionários do magistério serão concedidas as seguintes vantagens pecuniárias:

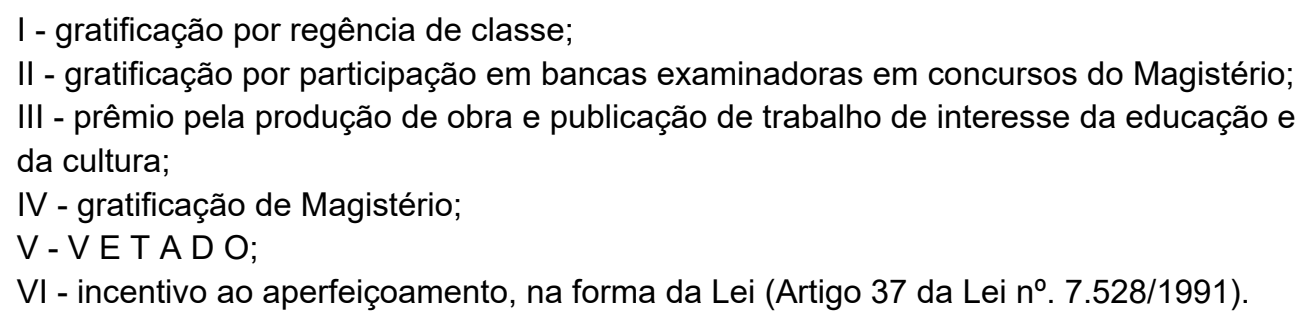

O professor, em regência de classe, receberá gratificação de vinte por cento $(20 \%)$ sobre o respectivo vencimento-base do cargo, gratificação que permanecerá até mesmo nos casos de readaptação (Artigo 38 da Lei $n^{\circ}$. 7.528/1991). O funcionário do Magistério terá direito também a todas as vantagens previstas no Estatuto dos Funcionários Públicos do Município de Belém (Artigo 40 da Lei no. 7.528/1991).

Para efeito de remuneração do Servidor do Magistério, será considerado cada mês constituído de cinco semanas (Artigo 41 da Lei $n^{\circ}$. 7.528/1991). O funcionário que completar vinte e cinco anos de efetivo exercício em atividades próprias do Magistério receberá, 
automaticamente, a gratificação de Magistério, correspondente a dez por cento do vencimento-base (10\%) (Artigo 39 da Lei $n^{\circ} .7 .528 / 1991$ ).

A remuneração dos professores da Funbosque conta com um elemento diferenciado em sua composição, a Gratificação Escola Bosque, instituída pela Lei Ordinária n. ${ }^{\circ} 7747,02$ de janeiro de 1995, que, em seu artigo 10 , parágrafo $4^{\circ}$, determina que:

Todos os servidores da Fundação Centro de Referência em Educação Ambiental 'Escola Bosque Professor Eidorfe Moreira', com exceção dos ocupantes de cargos comissionados, farão jus à gratificação EB (Escola Bosque) especial, correspondente a $80 \%$ (oitenta por cento) do vencimento base relativo a 30 (trinta) horas semanais.

A Lei n. ${ }^{\circ} 7.673$, de 21 de dezembro de 1993, determina percentuais de gratificação a serem incluídos na remuneração do professor pela formação em cursos de pós-graduação: de aperfeiçoamento; lato e stricto sensu, na ordem de:
I. $35 \%$ para possuidores de diploma de doutorado;
II. $30 \%$ para possuidores de diploma de mestrado;
III. $25 \%$ para possuidores de curso de especialização com carga horária igual ou superior a 360 horas;
IV. $40 \%$ para possuidores de diploma de graduação para os ocupantes de cargo de nível médio;
V. $7,5 \%$ para possuidores de curso de aperfeiçoamento com carga horária igual ou superior a 180 horas.

Em 02 de maio de 2016, Zenaldo Coutinho, prefeito de Belém, baixou o Decreto $\mathrm{n}^{\circ}$ 85.655, que instituiu o Abono Complementar, criado para garantir o repasse do valor percentual referente ao reajuste do salário mínimo à remuneração do professor. Contudo, como esse benefício foi concedido na forma de abono, não compondo o vencimento-base do professor, acabou não incidindo sobre as demais gratificações, o que fez com que o professor da Funbosque deixasse de ganhar 3,6\% de aumento na sua remuneração final em 2016.

$\mathrm{O}$ artigo $4^{\circ}$ do Decreto $\mathrm{n}^{\circ} 85.655 / 2016$ determina que:

No exercício de 2016, fica suspensa a possibilidade de ajustes de percentual, valor, índice ou quantidade, que altere o valor de vantagens e gratificações de qualquer natureza e resulte em aumento de despesas com pessoal e encargos sociais, exceto quando autorizado pelo Chefe do Executivo Municipal havendo melhora do quadro econômico.

Esse decreto permanece vigente até a presente data e tem acarretado em perdas salariais significativas para os docentes do município de Belém, haja vista que impossibilita a estes profissionais obter ganhos reais em suas gratificações, calculadas em cima do vencimento-base.

Para melhor compreensão da composição da remuneração dos professores da Funbosque, organizamos na Tabela 1 os dados referentes a esta remuneração, de professores lotados com jornadas de 240 horas/aula, concernentes à série histórica de 2009 a 2019. 
Tabela 1 - Composição da remuneração de professores da Funbosque lotados com jornada de 240 horas (Valor nominal)

\begin{tabular}{|c|c|c|c|c|c|c|c|c|}
\hline Ano & $\begin{array}{c}\text { Vencimento } \\
\text { Base }\end{array}$ & $\begin{array}{c}\text { Adicional de } \\
\text { Escolaridade } \\
(100 \%)\end{array}$ & $\begin{array}{l}\text { Regência } \\
\text { de Classe } \\
(20 \%)\end{array}$ & $\begin{array}{c}\text { Gratificação } \\
\text { Escola Bosque } \\
(80 \%)\end{array}$ & Abono & $\begin{array}{c}\text { Abono } \\
\text { Complementar }\end{array}$ & $\begin{array}{l}\text { Abono } \\
\text { Ind. }\end{array}$ & Total \\
\hline 2009 & $1.209,00$ & $1.209,00$ & 241,80 & 967,20 & 18,81 & - & - & $3.654,81$ \\
\hline 2010 & $1.326,00$ & $1.326,00$ & 265,20 & $1.060,80$ & 18,81 & - & - & $3.996,81$ \\
\hline 2011 & $1.334,16$ & $1.334,16$ & 266,83 & $1.067,33$ & 18,81 & - & - & $4.021,29$ \\
\hline 2012 & $1.492,80$ & $1.492,80$ & 298,56 & $1.194,24$ & 18,81 & - & - & $4.497,21$ \\
\hline 2013 & $1.808,00$ & $1.808,00$ & 361,60 & $1.446,40$ & 18,81 & - & - & $5.442,81$ \\
\hline 2014 & $1.930,66$ & $1.930,66$ & 386,13 & $1.544,53$ & 18,81 & - & - & $5.810,79$ \\
\hline 2015 & $2.123,73$ & $2.123,73$ & 424,74 & $1.698,98$ & 18,81 & - & - & $6.389,99$ \\
\hline 2016 & $2.229,91$ & $2.229,91$ & 445,98 & $1.783,93$ & 18,81 & 131,69 & - & $6.840,23$ \\
\hline 2017 & $2.229,91$ & $2.229,91$ & 445,98 & $1.783,93$ & 18,81 & 131,69 & 100,00 & $6.940,23$ \\
\hline 2018 & $2.296,82$ & $2.296,82$ & 459,36 & $1.837,46$ & 18,81 & 139,32 & 100,00 & $7.148,59$ \\
\hline 2019 & $2.342,77$ & $2.342,77$ & 468,55 & $1.874,22$ & 18,81 & 141,90 & 100,00 & $7.289,02$ \\
\hline
\end{tabular}

Fonte: Elaborada pelas autoras com base nos Contracheques dos professores da Funbosque.

Os dados referentes à remuneração dos professores da Funbosque em valores nominais constantes na Tabela 1 nos possibilita inferir que a composição da sua remuneração esteve majoritariamente concentrada, de 2009 a 2015, em cinco elementos, a saber: i) vencimento-base; ii) adicional de escolaridade; iii) gratificação de regência de classe; iv) gratificação Escola Bosque; e v) abono.

Em 2016 observamos que surgiu um novo elemento, o abono complementar, que concentrou o reajuste do salário mínimo na forma de abono sem incorporá-lo ao vencimentobase, acarretando em impacto negativo nas demais gratificações, que são calculadas sobre este vencimento. Em 2017 surge outro elemento, que aparece no contracheque dos professores da Funbosque com a nomenclatura de "abono ind", no valor fixo de R $\$ 100,00$, pago aos professores independentemente da carga horária de trabalho que possuam.

Os dados evidenciam que a partir de 2016 os reajustes, que deveriam ser concedidos aos professores da Funbosque, acabaram concentrados na forma de abono, o que acarretou em ausência de maiores ganhos para os professores em suas gratificações, que são calculadas sobre seu vencimento-base.

$\mathrm{Na}$ Tabela 2, organizamos os dados da remuneração com vistas a evidenciar a participação percentual do vencimento-base e das gratificações na remuneração dos professores da Funbosque, em início de carreira com jornada de 240 horas mensais, relativos ao período de 2009 a 2019. 
Tabela 2 - Participação percentual do vencimento-base e gratificações na remuneração dos professores da Funbosque, em início de carreira, no período de 2009 a 2019 - com jornada 40h semanais (em R\$)

\begin{tabular}{c|c|c|c}
\hline \multirow{2}{*}{ ANO } & \multicolumn{3}{|c}{ JORNADA DE 240 HORAS } \\
\cline { 2 - 4 } & Remuneração & Vencimento \% & $\begin{array}{c}\text { Gratificações } \\
\%\end{array}$ \\
\hline $\mathbf{2 0 0 9}$ & $3.654,81$ & 33,0 & 67,0 \\
\hline $\mathbf{2 0 1 0}$ & $3.996,81$ & 33,1 & 66,9 \\
\hline $\mathbf{2 0 1 1}$ & $4.021,29$ & 33,1 & 66,9 \\
\hline $\mathbf{2 0 1 2}$ & $4.497,21$ & 33,1 & 66,9 \\
\hline $\mathbf{2 0 1 3}$ & $5.442,81$ & 33,2 & 66,8 \\
\hline $\mathbf{2 0 1 4}$ & $5.810,79$ & 33,2 & 66,8 \\
\hline $\mathbf{2 0 1 5}$ & $6.389,99$ & 33,2 & 66,8 \\
\hline $\mathbf{2 0 1 6}$ & $6.840,23$ & 32,5 & 67,5 \\
\hline $\mathbf{2 0 1 7}$ & $6.940,23$ & 32,1 & 67,9 \\
\hline $\mathbf{2 0 1 8}$ & $7.148,59$ & 32,1 & 67,9 \\
\hline $\mathbf{2 0 1 9}$ & $7.289,02$ & 32,1 & 67,9 \\
\hline
\end{tabular}

Fonte: Elaborada pelas autoras com base nos contracheques dos professores da Funbosque.

Os dados da Tabela 2 nos mostram claramente o impacto percentual que as gratificações têm na remuneração final dos professores da Funbosque. Observamos que, ao longo da série histórica em análise (2009-2019), a relação estabelecida entre as gratificações e o vencimento-base foi em média de $32,7 \%$ de vencimento e $67,2 \%$ de remuneração, que pode ser explicada pelo peso que tem a gratificação Escola Bosque (de $80 \%$ ) na remuneração desses docentes. Observamos ainda que, desde 2009, as gratificações representam cerca de dois terços da remuneração do professor, apresentando um pequeno aumento da participação no período.

Pereira (2017) observou que, dentre a remuneração dos demais professores da rede municipal de Belém (não vinculados à Funbosque), essa relação entre gratificações e vencimento-base era de $60 \%$ a $40 \%$, o que também revela impacto significativo das gratificações na composição da remuneração desses docentes, contudo em menor medida que o observado entre os professores da Funbosque.

Consideramos importante analisar o poder de compra proporcionado pelo vencimentobase dos professores da Funbosque em relação a outros indicadores. Para isso, os dados da Tabela 3 nos permitem estabelecer comparações entre o vencimento-base dos docentes da Funbosque e o salário mínimo nominal e necessário do Departamento Intersindical de Estatística e Estudos Socioeconômicos (DIEESE) ${ }^{3}$, que consiste num valor de salário calculado para sustentar uma família de quatro pessoas. Os outros indicadores escolhidos foram o valor do salário mínimo vigente no Brasil e o valor do Piso Salarial Profissional Nacional (PSPN) do magistério, de 2009 a 2019.

Esclarecemos que optamos por utilizar o vencimento-base ao invés da remuneração total como valor de referência na comparação, apoiadas em Sales e França (2018, p. 467), que argumentam que:

O vencimento representa a parte fixa do montante recebido pelo docente ao final do mês, sem qualquer tipo de acréscimo. Portanto, a política de reajuste salarial incide diretamente sobre esse elemento no contracheque. No caso da remuneração, ela

3 Trata-se de um valor de salário calculado para sustentar uma família de quatro pessoas, segundo o DIEESE. 
representa 0 montante recebido, incluindo o vencimento e outros componentes recebidos pelo trabalhador, por exemplo, as gratificações, os abonos, entre outros.

Esclarecido isso, passemos à Tabela 3:

Tabela 3 - Valor do salário mínimo necessário do DIEESE, salário mínimo nacional, PSPN e vencimento-base dos professores da Funbosque, em início de carreira, no período de 2009 a 2019 com jornada de $240 \mathrm{~h}$ com nível superior (em $R \$$ )

\begin{tabular}{|c|c|c|c|c|c|c|c} 
Ano & $\begin{array}{c}\text { Salário mínimo } \\
\text { necessário } \\
\text { DIEESE } \\
\text { (a) }\end{array}$ & $\begin{array}{c}\text { Salário } \\
\text { mínimo } \\
\text { nacional } \\
\text { (b) }\end{array}$ & $\begin{array}{c}\text { PSPN } \\
\text { (c) }\end{array}$ & $\begin{array}{c}\text { Vencimento-base } \\
\text { do professor da } \\
\text { Funbosque } \\
\text { (d) }\end{array}$ & (d/a) & (d/b) & (d/c) \\
\hline $\mathbf{2 0 0 9}$ & $2.085,89$ & 465,00 & 950,00 & $1.209,00$ & 57,9 & 260,0 & 127,3 \\
\hline $\mathbf{2 0 1 0}$ & $2.132,09$ & 510,00 & $1.024,02$ & $1.326,00$ & 42,3 & 260,0 & 129,4 \\
\hline $\mathbf{2 0 1 1}$ & $2.329,94$ & 545,00 & $1.187,02$ & $1.334,16$ & 57,0 & 244,8 & 112,3 \\
\hline $\mathbf{2 0 1 2}$ & $2.617,33$ & 622,00 & $1.451,00$ & $1.492,80$ & 57,0 & 240,0 & 102,8 \\
\hline $\mathbf{2 0 1 3}$ & $2.729,24$ & 678,00 & $1.567,00$ & $1.808,00$ & 66,2 & 266,0 & 115,3 \\
\hline $\mathbf{2 0 1 4}$ & $2.967,07$ & 724,00 & $1.697,00$ & $1.930,66$ & 65,0 & 266,6 & 113,7 \\
\hline $\mathbf{2 0 1 5}$ & $3.210,28$ & 788,00 & $1.917,78$ & $2.123,73$ & 66,1 & 269,5 & 110,7 \\
\hline $\mathbf{2 0 1 6}$ & $4.016,27$ & 880,00 & $2.135,64$ & $2.229,91$ & 55,5 & 253,3 & 104,4 \\
\hline $\mathbf{2 0 1 7}$ & $3.754,16$ & 937,00 & $2.298,83$ & $2.229,91$ & 59,3 & 237,9 & 97,0 \\
\hline $\mathbf{2 0 1 8}$ & $3.783,39$ & 954,00 & $2.455,35$ & $2.296,82$ & 60,7 & 240,7 & 93,5 \\
\hline $\mathbf{2 0 1 9}$ & $3.980,82$ & 998,00 & $2.557,74$ & $2.342,77$ & 58,8 & 234,7 & 91,5 \\
\hline
\end{tabular}

Fonte: Elaborada pelas autoras com base em dados do DIEESE; Diário Oficial da União e contracheques dos professores da Funbosque. Nota 1: Valores nominais.

A comparação entre o vencimento-base do professor da Funbosque e o salário mínimo necessário do DIEESE (d/a), constantes na Tabela 3, permite-nos afirmar que, ao longo de toda a série histórica, os dois valores não se equipararam $O$ máximo que o vencimento-base do professor da Funbosque se aproximou desse indicador foi no ano de 2013, quando chegou a representar $66,2 \%$ do salário mínimo necessário do DIEESE.

Entre 2016 e 2017 essa relação decaiu em torno de 5\%, voltando a crescer em 2018, mas encerrando a série histórica com perda. Inferimos que esse movimento pode ter sido influenciado pela não incorporação do reajuste salarial ao vencimento-base do professor da Funbosque, o que certamente teve impacto na sua remuneração, e consequente redução do poder de compra.

No que se refere à relação entre o vencimento-base do professor da Funbosque e o salário mínimo nacional $(\mathrm{d} / \mathrm{b})$, observamos que também ocorreu significativa redução e desvalorização salarial. Ao longo da série histórica é possível perceber que o vencimentobase do professor da Funbosque era acima de 2,5 salários mínimos em média, relação que se manteve estável até o ano de 2015. Contudo, a partir de 2016, observamos um movimento de queda, que se intensificou e se manteve até o final de série histórica. Assim, em 2019, o vencimento-base do professor da Funbosque representava apenas pouco mais de 2,3 salários mínimos.

Ao considerarmos a relação entre o vencimento-base do professor da Funbosque e o valor do PSPN (d/c), observamos que as perdas são intensificadas. No ano de 2010, o vencimento-base do professor da Funbosque estava $29,4 \%$ acima do valor do PSPN, porém, ao longo da série histórica, esse valor foi decaindo, até atingir o percentual negativo de $-8,5 \%$. Assim, em 2019, o vencimento-base do professor da Funbosque representava apenas $91,5 \%$ do valor total estabelecido como valor do PSPN. 
Estudos sobre remuneração docente, como o de Sales e França (2018), têm chamado a atenção para o fato de que, desde 2009 , o crescimento do valor mínimo nacional por aluno/ano acima da inflação tem contribuído indiretamente para a elevação dos valores do PSPN, visto que sua atualização anual acompanha a variação do valor-aluno do Fundef/Fundeb (valor mínimo nacional por aluno/ano), cuja variação considera sempre os dois últimos anos, conforme estabelecido no Parágrafo Único do artigo $5^{\circ}$ da Lei $11.738 / 2008$. O valor mínimo nacional por aluno/ano cresceu nominalmente $223,5 \%$, referenciando-se 116,6 pontos percentuais acima do percentual acumulado pelo Salário Mínimo, que foi de 106,9\% (SALES; FRANÇA, 2018).

Contraditoriamente, o estabelecimento do PSPN trouxe consequências negativas aos professores da Funbosque, que antes ganhavam valor de vencimento-base superior a esse piso, que depois foi diminuindo até ficar abaixo dele. Além disso, é importante destacar que o PSPN foi estabelecido tendo como referência o professor com formação em nível médio magistério, profissional que não existe no quadro docente da Funbosque, já que todos possuem formação em nível superior, o que tende a tornar mais contraditória a situação desses professores.

Sales e França (2008, p. 471) sublinham os efeitos do PSPN na carreira e na remuneração de professores das redes estaduais e municipais de ensino brasileiras, uma vez que:

[...] embora o PSPN tenha, indiretamente, impactado a remuneração dos professores, sua implantação sofreu impacto direto e expressivo no valor do vencimento, uma vez que contribuiu decisivamente para aproximar os valores do vencimento e da remuneração.

Esse movimento observado pelos autores não foi sentido em tanta medida pelos professores da Funbosque no que se refere ao valor final da remuneração, muito em parte devido ao impacto significativo que a gratificação Escola Bosque de $80 \%$, aliada a outras gratificações, tem nessa remuneração, mas contribuiu para que o vencimento-base fosse diminuindo até ficar abaixo do valor do PSPN.

Com isso, tem-se desenvolvido um processo de achatamento da carreira dos professores da Funbosque. Esse é um fenômeno observado por diversos autores que tratam do PSPN, tais como Bassi e Gil (2015, p. 12) quando afirmam que:

A aprovação desta medida possibilitou que a tabela de vencimentos incorporasse os valores do PSPN no início da carreira do magistério, mas ao custo de reduzir o percentual de distância entre as referências superiores provocando o achatamento da carreira. Quer dizer, a equiparação do vencimento inicial ao valor do piso nacional não foi acompanhada da elevação na mesma proporção dos outros vencimentos até o vencimento final. A redução na dispersão da carreira - a distância entre o menor e o maior vencimento -, atesta isso.

$\mathrm{Na}$ Tabela 4 organizamos dados referentes ao rendimento médio mensal de professores da Educação Básica, que possuem uma única ocupação, ou seja, somente um vínculo empregatício com jornada de 40 horas semanais. Utilizamos as médias de remuneração do Instituto de Pesquisa Econômica Aplicada (IPEA) (2017) de professores que tinham vínculo no ensino público nas redes federal, estadual e municipal, na perspectiva de comparar os rendimentos auferidos por esses professores com os do docente da Funbosque. 
Para a análise, utilizamos o ano de 2015, que foi o mesmo escolhido pelo estudo realizado pelo IPEA.

Tabela 4 - Rendimento médio mensal de professores da Educação Básica com uma única ocupação e jornada de $\mathbf{4 0}$ horas semanais em comparação com a remuneração do professor da Funbosque (2015)

\begin{tabular}{|c|c|c|c|}
\hline \multirow{2}{*}{ Região e local de domicílio } & \multicolumn{3}{|c}{ Esfera administrativa } \\
\hline \multirow{2}{*}{ Norte (Região Metropolitana } & Federal & Estadual & Municipal \\
\cline { 2 - 4 } & 5.806 & 3.535 & 2.771 \\
\hline Brasil (Região Metropolitana) & 5.009 & 2.852 & 2.492 \\
\hline Professor da Funbosque & \multicolumn{3}{|c}{6.389} \\
\hline
\end{tabular}

Fonte: IPEA (2017). Nota: Valores nominais.

Os dados da Tabela 4 nos permitem inferir que a remuneração dos professores da Funbosque é significativamente superior à remuneração dos professores que possuem vínculo empregatício com estados e municípios brasileiros, é até mesmo superior à remuneração de professores de Educação Básica com vínculo com a esfera federal.

Contudo, é importante destacar que os professores da Funbosque são apenas 135, constituindo-se em um universo pequeno de profissionais se comparados ao total de docentes da rede municipal de ensino de Belém/PA, visto que a Funbosque é apenas uma das instituições vinculadas à rede municipal, composta por 129 escolas no total.

Com a finalidade de analisar comparativamente a remuneração dos professores da Funbosque, reunimos na Tabela 5 dados referentes à remuneração de profissionais cuja função exigia o mesmo nível de formação dos professores da Funbosque, e que fossem funcionários efetivos da prefeitura de Belém.

Tabela 5 - Vencimento e remuneração inicial mensal de servidores públicos municipais de Belém, com formação em nível superior (2013)

\begin{tabular}{c|l|c|c|c}
\hline Nível & \multicolumn{1}{|c|}{ Profissão } & $\begin{array}{c}\text { Carga Horária } \\
\text { (semanal) }\end{array}$ & $\begin{array}{c}\text { Vencimento- } \\
\text { Base }\end{array}$ & Remuneração \\
\hline \multirow{5}{*}{ Superior } & $\begin{array}{l}\text { Arquiteto, Assistente Social, } \\
\text { Bibliotecário, Contador, } \\
\text { Economista. }\end{array}$ & $30 \mathrm{~h}$ & 710 & 1.421 \\
\cline { 2 - 5 } & $\begin{array}{l}\text { Engenheiro Civil, } \\
\text { Engenheiro mecânico, } \\
\text { Engenheiro Químico. }\end{array}$ & $30 \mathrm{~h}$ & 710 & 1.421 \\
\cline { 2 - 5 } & $\begin{array}{l}\text { Biomédico, Biólogo, } \\
\text { Fisioterapeuta, Médico, } \\
\text { Odontólogo, Psicólogo }\end{array}$ & $30 \mathrm{~h}$ & 710 & 1.421 \\
\cline { 2 - 5 } & Professor da rede municipal & 40h & 1.883 & 4.163 \\
\cline { 2 - 5 } & Professor da Funbosque & $40 \mathrm{~h}$ & 1.808 & 5.442 \\
\hline
\end{tabular}

Fonte: Tabelas de Remuneração/2013 da Prefeitura Municipal de Belém4.

Os dados da Tabela 5 nos permitem afirmar que há diferença significativa entre a remuneração dos professores da Funbosque e as dos demais funcionários com formação de nível superior da prefeitura de Belém. Contudo, precisamos olhar os dados mais detidamente, visto que esses profissionais cumprem jornadas de 30 horas semanais e trabalham em condições diferentes à dos professores da Funbosque, que lhes permite acúmulo de funções,

4 Disponível em: https://leismunicipais.com.br/a/pa/b/belem/decreto/2013/7596/75965/decreto-n-75965-2013dispoe-sobre-a-remuneracao-dos-servicos-e-da-utilizacao-dos-imoveis-da-codem-pela-administracao-diretae-indireta-do-municipio-de-belem-e-da-outras-providencias. Acesso em: 02 fev. 2020. 
a exemplo das profissões na área da saúde. Outro fator a se considerar é o fato de que esses outros profissionais dificilmente cumprem jornadas extras de trabalho, conseguindo cumprir todas as suas demandas dentro do horário destinado para esse fim, diferentemente do professor.

É importante ressaltar o impacto equilibrado que as gratificações têm na composição da remuneração desses diversos profissionais, na ordem de $50 \%$, enquanto que, na remuneração dos professores da Funbosque, as gratificações chegaram a representar $66,7 \%$ da remuneração no ano de 2013. No que se refere aos demais professores da rede municipal de ensino de Belém, observamos que o impacto das gratificações na composição da sua remuneração, embora seja menor que o observado na Funbosque, ainda é bastante significativo, representando mais da metade da remuneração $(55 \%)$ desses profissionais.

$\mathrm{Na}$ Tabela 6 organizamos os dados referentes à remuneração dos professores da Funbosque, em valores atualizados pelo Índice Nacional de Preços ao Consumidor do Instituto Brasileiro de Geografia e Estatística (INPC/IBGE) ${ }^{5}$, com a finalidade de compreender o ganho real que esses profissionais tiveram durante a série histórica de 2009 a 2019. O INPC/IBGE é obtido a partir dos Índices de Preços ao Consumidor regionais e tem como objetivo oferecer a variação dos preços no mercado varejista, mostrando, assim, o aumento do custo de vida da população.

Tabela 6 - Evolução da remuneração dos professores da Funbosque (2009/2019)

\begin{tabular}{c|c|c}
\hline ANO & $\begin{array}{c}\text { REMUNERAÇÃO } \\
\text { JORNADA DE 240H }\end{array}$ & No Índice (\%) \\
\hline $\mathbf{2 0 0 9}$ & $6.453,89$ & 100 \\
\hline $\mathbf{2 0 1 0}$ & $6.736,62$ & 104,3 \\
\hline $\mathbf{2 0 1 1}$ & $6.372,63$ & 98,7 \\
\hline $\mathbf{2 0 1 2}$ & $6.757,19$ & 104,6 \\
\hline $\mathbf{2 0 1 3}$ & $7.659,50$ & 118,6 \\
\hline $\mathbf{2 0 1 4}$ & $7.759,50$ & 120,2 \\
\hline $\mathbf{2 0 1 5}$ & $7.924,42$ & 122,7 \\
\hline $\mathbf{2 0 1 6}$ & $7.636,78$ & 118,3 \\
\hline $\mathbf{2 0 1 7}$ & $7.401,02$ & 114,6 \\
\hline $\mathbf{2 0 1 8}$ & $7.487,48$ & 116,0 \\
\hline $\mathbf{2 0 1 9}$ & $7.345,15$ & 113,8 \\
\hline
\end{tabular}

Fonte: Elaborada pelas autoras com base nos Contracheques dos professores da Funbosque. Nota: Valores corrigidos a preços de $1^{\circ}$ de março de 2019, INPC/IBGE.

Por meio dos dados da Tabela 6 percebemos que, com exceção do ano de 2011, a remuneração dos professores da Funbosque vinha crescendo até o ano de 2015, quando começou a apresentar decréscimo, que se manteve até o final da série histórica. O auge do crescimento da remuneração do professor da Funbosque, em 2015, foi de 22,7\% em relação à remuneração de 2009 para os professores com jornada de 240 horas. Em 2016 houve queda abrupta de 4,4\% em relação ao ano anterior para os mesmos professores. Ao final da série histórica, houve ganho real na remuneração de 13,8\% para os professores com jornada de 240 horas. Não obstante, esse crescimento poderia ter sido maior caso os reajustes fossem feitos no vencimento-base e não em forma de gratificações, como ocorreu com a criação do abono complementar e do "abono ind" a partir de 2016 e 2017, respectivamente.

5 O INPC/IBGE é obtido a partir dos Índices de Preços ao Consumidor regionais e tem como objetivo oferecer a variação dos preços no mercado varejista, mostrando, assim, o aumento do custo de vida da população. 


\section{Considerações Finais}

Ao longo deste artigo vimos que, na proposta de criação da Funbosque, apresentavamse muitas expectativas em torno do futuro professor da Fundação, principalmente no que se refere às funções que o docente deveria atender, bem como às competências que ele deveria dominar para que correspondesse à expectativa de profissional polivalente que a Fundação anunciava em seu projeto pedagógico. Com vistas a atrair os melhores professores, foi estabelecido um adicional que se configurou como um diferencial significativo, a gratificação Escola Bosque, paga no percentual de $80 \%$ calculado em cima do valor do vencimento-base, para que possibilitasse ao docente da Funbosque uma remuneração mais elevada em relação aos demais professores da rede municipal de ensino de Belém.

A análise da evolução da remuneração dos professores da Funbosque, na série histórica compreendida entre o período de 2009 a 2019, permite-nos afirmar que os valores recebidos por esses professores garantem uma boa atratividade à carreira, visto que são valores bem maiores quando comparados à remuneração paga a profissionais com o mesmo nível de formação e que possuem vínculo efetivo de emprego com a Prefeitura Municipal de Belém. O mesmo acontece quando comparamos a remuneração dos professores da Funbosque com as médias recebidas por professores de redes estaduais, municipais e professores federais da Educação Básica na região Norte e no Brasil.

Os dados referentes à composição da remuneração dos professores da Funbosque destacam o peso que as gratificações têm sobre sua remuneração, perfazendo a média de $67,2 \%$ de 2009 a 2019. Tal percentual é devido, principalmente, à gratificação Escola Bosque. Esse dado é preocupante, pois as gratificações se constituem em elementos transitórios e não fixos, podendo ser retirados a qualquer tempo e não sendo elemento computável para a aposentadoria e também por deixar evidente a falta de equidade existente dentro da mesma rede de ensino, em que professores vinculados à Funbosque gozam de remuneração $32 \%$ superior à dos demais professores que atuam em outras instituições de ensino do município de Belém. A opção em compor a remuneração dos professores da Funbosque majoritariamente de gratificações tende a gerar impactos positivos imediatos pelos reajustes anuais concedidos, mas também resultados futuros imprevisíveis, como no momento da aposentadoria desses docentes.

Constatamos, ainda, que o vencimento-base dos professores da Funbosque desde 2016 tem tido pouco crescimento e até estagnação nos valores, o que vem resultando em seu achatamento, a ponto de não apenas ter se equiparado ao PSPN, mas, a partir de 2017 , ter ficado abaixo do valor do piso salarial nacional dos docentes da educação básica, à revelia da lei, ainda que na Funbosque todos os professores tenham formação de nível superior. Essa situação, proporcionada, a nosso ver, pela opção da gestão municipal em pagar reajustes salariais anuais na forma de abonos, ao invés de agregá-los ao vencimento-base, tal como concebido por Sales e França (2018), tem propiciado ausência de ganhos maiores no valor final da remuneração. Ainda assim, consideramos que o valor da remuneração dos professores da Funbosque contribui bastante para a atratividade do ingresso na carreira docente naquela instituição de ensino. 
Funbosque

\section{Referências}

BASSI, Marcos Edgar; GIL, I-Juca. Remuneração de Professores de Escolas Públicas no Contexto do Fundeb e PSPN. In: GOUVEIA, Andréa Barbosa; PINTO, José Marcelino de Rezende; FERNANDES, Maria Dilnéia Espíndola. Financiamento da Educação no Brasil. Campo Grande: Oeste, 2015. p. 257-279.

BELÉM. Prefeitura Municipal. Lei Orgânica do Município de Belém. Aprovada de 30/03/1990. Diário Oficial do Município de Belém, Belém, 1990a. Disponível em: http://www.belem. pa.gov.br/semaj/app/Sistema/form_leis_2.php. Acesso em: 02 set. 2016.

BELÉM. Prefeitura Municipal. Lei 7.502 de 20 de dezembro de 1990 - Dispõe sobre o Estatuto do Funcionário Público de Belém. Diário Oficial do Município de Belém, Belém, 1990b. Disponível em: http://www.belem.pa.gov.br/semaj/app/Sistema/form_leis_2.php. Acesso em: 02 set. 2016.

BELÉM. Prefeitura Municipal. Lei n 7.528, de 5 de agosto de 1991 - Estatuto do Magistério. Diário Oficial do Município de Belém, Belém, 1991. Disponível em: http://www.belem.pa. gov.br/semaj/app/Sistema/form_leis_2.php. Acesso em: 02 set. 2016.

BELÉM. Prefeitura Municipal. Lei no 7673 de 21 de dezembro de 1993 - Dispõe sobre o sistema de promoção do grupo magistério da secretaria municipal de educação. Diário Oficial do Município de Belém, Belém, 1993. Disponível em: https://cmbelem.jusbrasil.com.br/legislacao/583728/lei-7673-93. Acesso em: 20 jun. 2020.

BELÉM. Prefeitura Municipal. Lei 7.747, de 02 de Janeiro de 1995. Autoriza o poder Executivo a criar o centro de referência em educação ambiental - Escola Bosque professor Eidorfe Moreira, na ilha de Caratateua, distrito de Outeiro, município de Belém e dá outras providências. Diário Oficial do Município de Belém, Belém, 1995.

BELÉM. Prefeitura Municipal. Decreto n 85.655 de 02 de maio de 2016. Estabelece medidas de contenção e redução de despesas e limitação de empenho no âmbito do Poder Executivo, e dá outras providências. Diário Oficial do Município de Belém, Belém, 2016.

DEMO, Pedro. Educação e desenvolvimento sustentável: sobre o enfoque integrado do desenvolvimento. Caminhos da Educação. Belém: PMB/SEMEC, 1996. Série Planejamento, n. 4.

PEREIRA, Fernanda Maryelle. As Políticas de Remuneração Inicial para os Professores da Educação Básica da Rede Municipal de Ensino de Belém no Período de 1991 a 2013. 2017. Dissertação (Mestrado em Educação) - Universidade Federal do Pará, Belém, 2017.

PINHEIRO, Raimundo Walber da Silva. Políticas de Remuneração de Professores da Educação Básica em Municípios do Estado do Pará. 2017. Dissertação (Mestrado em Educação) - Universidade Federal do Pará, Belém, 2017.

SALES, Luís Carlos; FRANÇA, Magna. Efeitos da Lei do Piso nos vencimentos de professores do Piauí e do Rio Grande do Norte no contexto da política de fundos. RBPAE, v. 34, n. 2, p. 461 - 478, maio/ago. 2018.

SILVA, Marilena Loureiro da. A Escola Bosque e suas estruturas educadoras: uma casa de Educação Ambiental. In: TRAJBER, Rachel; MELLO, Soraia (Org.). Vamos Cuidar do Brasil 
com as escolas. Conceitos e Práticas de Educação Ambiental na escola. Brasília: MEC/MMA/UNESCO, 2007. p. 115-122.

Danielle Cristina de Brito Mendes é pedagoga do Instituto de Ciências da Educação da Universidade Federal do Pará; aluna do Doutorado Acadêmico do Programa de PósGraduação em Educação da Universidade Federal do Pará.

ORCID: http://orcid.org/0000-0001-9238-8425

E-mail: dany.britto@hotmail.com

Dalva Valente Guimarães Gutierres é professora associada da graduação e da pósgraduação em Educação (Mestrado e Doutorado) da Universidade Federal do Pará; orientadora de Mestrado e Doutorado.

ORCID: http://orcid.org/0000-0002-5157-6400

E-mail: dalva.valente@gmail.com 


\section{Editores do volume 11}

Márcia Aparecida Jacomini - Universidade Federal de São Paulo, Brasil

José Marcelino de Rezende Pinto - Universidade de São Paulo, Brasil

\section{Comitê Editorial}

Nalú Farenzena - Universidade Federal do Rio Grande do Sul, Brasil

Juca Gil - Universidade Federal do Rio Grande do Sul, Brasil

Theresa Adrião - Universidade Estadual de Campinas, Brasil

Ângelo Ricardo de Souza - Universidade Federal do Paraná, Brasil

\section{Conselho Editorial}

\section{Alejandro Morduchowicz}

Universidad Pedagógica, Provincia de Buenos Aires, Argentina

Andréa Barbosa Gouveia

Universidade Federal do Paraná, Brasil

Fernanda Saforcada

Universidade de Buenos Aires, Argentina

Jacques Velloso

Universidade de Brasília, Brasil

João Monlevade

Senado Federal, Brasil

Jorge Abrahão de Castro

Instituto de Pesquisa Econômica Aplicada / IPEA, Brasil

Lisete Regina Gomes Arelaro

Universidade de São Paulo, Brasil

Luis Carlos Sales

Universidade Federal do Piauí, Brasil

Luiz de Sousa Junior

Universidade Federal da Paraíba, Brasil

Luiz Fernandes Dourado

Universidade Federal de Goiás, Brasil

Magna França

Universidade Federal do Rio Grande do Norte, Brasil

Marcos Edgar Bassi

Universidade Federal de Santa Catarina, Brasil

Maria Angélica Pedra Minhoto

Universidade Federal de São Paulo, Brasil

Maria Beatriz Luce

Universidade Federal do Rio Grande do Sul, Brasil

Maria Dilnéia Espíndola Fernandes

Universidade Federal de Mato Grosso do Sul, Brasil

Nelson Cardoso do Amaral

Universidade Federal de Goiás, Brasil

Nicholas Davies

Universidade Federal Fluminense, Brasil

Robert E. Verhine

Universidade Federal da Bahia, Brasil

Romualdo Portela de Oliveira

Universidade de São Paulo, Brasil

Rosana Gemaque Rolim

Universidade Federal do Pará, Brasil

Rubens Barbosa de Camargo

Universidade de São Paulo, Brasil

Theresa Adrião

Universidade Estadual de Campinas, Brasil

Tristan McCowan

University of London, Reino Unido

Vera Jacob

Universidade Federal do Pará, Brasil

Vera Peroni

Universidade Federal do Rio Grande do Sul, Brasil

Vitor Henrique Paro

Universidade de São Paulo, Brasil

\section{Equipe editorial}

Apoio ao Comitê Editorial: Caio Cabral da Silva

Diagramação, Revisão de português e normalização: Edson Leonel de Oliveira

Revisão de inglês: Sabrina Ferreira

Fineduca - Revista de Financiamento da Educação

Associação Nacional de Pesquisa em

Financiamento da Educação

e-mail: revista.fineduca@gmail.com | site: http://seer.ufrgs.br/fineduca 